\title{
A Statewide, Population-Based Time- Series Analysis of the Increasing Frequency of Nonoperative Management of Abdominal Solid Organ Injury
}

Robert Rutledge, M.D., F.A.C.S., John P. Hunt, M.D, Christopher W. Lentz, M.D., Samir M. Fakhry, M.D., F.A.C.S., Anthony A. Meyer, M.D., Ph.D., F.A.C.S.,

Christopher C. Baker, M.D., F.A.C.S., and George F. Sheldon, M.D., F.A.C.S.

From the Department of Surgery, University of North Carolina at Chapel Hill, Chapel Hill, North Carolina

\section{Introduction}

Emergency operative intervention has been one of the cornerstones of the care of the injured patient. Over the past several years, nonoperative management has increasingly been recommended for the care of selected blunt abdominal solid organ injuries. The purpose of this study was to utilize a large statewide, population-based data set to perform a time-series analysis of the practice of physicians caring for blunt solid organ injury of the abdomen. The study was designed to assess the changing frequency and the outcomes of operative and nonoperative treatments for blunt hepatic and splenic injuries.

\section{Methods}

Data were obtained from the state hospital discharge data base, which tracks information on all hospitalized patients from each of the 157 hospitals in the state of North Carolina. All trauma patients who had sustained injury to a solid abdominal organ (kidney, liver, or spleen) were selected for initial analysis.

\section{Results}

During the 5 years of the study, 210,256 trauma patients were admitted to the state's hospitals $(42,051 \pm 7802$ per year). The frequency of nonoperative interventions for hepatic and splenic injuries increased over the period studied. The frequency of nonoperative management of hepatic injuries increased from $55 \%$ in 1988 to $79 \%$ in 1992 in patients with hepatic injuries and from $34 \%$ to $46 \%$ in patients with splenic injuries. The rate of nonoperative management of hepatic injuries increased from $54 \%$ to $64 \%$ in nontrauma centers compared with an increase from $56 \%$ to $74 \%$ in trauma centers $(p=0.01)$. In patients with splenic injuries, the rate of nonoperative management increased from $35 \%$ to $44 \%$ in nontrauma centers compared with an increase from $33 \%$ to $49 \%$ in trauma centers $(p<0.05)$. The rate of nonoperative management was associated with the organ injury severity, ranging from $90 \%$ for minor injuries to $19 \%-40 \%$ for severe injuries. Finally, in an attempt to compare blood use in operatively and nonoperatively treated patients, the total charges for blood were compared in the two groups. When compared, based on organ injury severity, the total blood used, as measured by charges, was lower for nonoperatively treated patients. 


\section{Conclusions}

This large, statewide, population-based time-series analysis shows that the management of blunt injury of solid abdominal organs has changed over time. The incidence of nonoperative management for both hepatic and splenic injuries has increased. The study indicates that the rates of nonoperative management vary in relation to the severity of the organ injury. The rates of increase in nonoperative management were greater in trauma centers than in nontrauma centers. These findings are consistent with the hypothesis that this newer approach to the care of blunt injury of solid abdominal organs is being led by the state's trauma centers.

Trauma has been recognized as one of America's most serious and expensive health care problems. ${ }^{1}$ In today's environment of rising costs and diminishing health care resources, treatment of injury needs to be delivered in the most effective and efficient manner possible. Surgical procedures are costly and invasive and ideally should be reserved for patients in whom such interventions can save lives, reduce pain and suffering, promote optimal recovery, and minimize lost productivity. To improve the quality of trauma care, there should be continued efforts to identify which patients benefit from operative interventions for injury. When ideal trauma care is maximized and the use of expensive resources is minimized, the best interests of the patient, the institution, and society will be served. The practice of nonoperative management of solid abdominal organ injuries in selected patients may allow delivery of optimum care to selected patients, while conserving resources.

Blunt abdominal injuries have traditionally been difficult to assess, and emergency surgical intervention to evaluate and treat blunt intra-abdominal injuries has been a cornerstone of the care of the injured patient. The development of peritoneal lavage, allowing detection of hemoperitoneum, was an important adjunct to the initial assessment of blunt intra-abdominal injury. ${ }^{2}$ More recently, the use of computed tomography (CT) has allowed physicians to assess solid abdominal organ injury and to estimate blood loss through cross-sectional imaging. ${ }^{3.4}$ These improving techniques of injury assessment have been associated with reports suggesting that the ideal management of selected solid organ injuries is through nonoperative treatment. ${ }^{5,6}$

This approach of using nonoperative management for selected blunt solid organ injuries was first applied to splenic injuries in children ${ }^{7,8}$ and more recently to hepatic injuries. ${ }^{9,10}$ Although many articles have described positive results with the nonoperative management of se-

Presented at the 115th Annual Meeting of the American Surgical Association, April 6-8, 1995, Chicago, Illinois.

Address reprint requests to Robert Rutledge, M.D., F.A.C.S., Chief of Medical Informatics, Associate Professor of Surgery, Department of Surgery, University of North Carolina at Chapel Hill, Campus Box 7210, Burnett-Womack, Chapel Hill, NC 27599-7210.

Accepted for publication April 10, 1995. lected patients with blunt solid organ injury, ${ }^{11-17}$ some surgeons are still suspicious of this approach because of the possibility of missed abdominal injuries, delayed recognition of significant intra-abdominal bleeding, and associated mismanagement of the patient with the attendant risks of morbidity and mortality. It is appropriate for physicians and surgeons to have a healthy skepticism of new techniques until the value of a new approach has been documented and the appropriate patients for such therapies clearly defined. The purpose of this study was to perform a time-series analysis of the frequency of solid abdominal organ injury and its management in a statewide, population-based data base. The unique nature of this data source is of great value in addressing questions related to the management of solid organ injury, because the data set includes information on all of the patients with solid organ injury hospitalized in all of the hospitals in the state of North Carolina for a 5-year period. Thus, this data set provides a true, unbiased picture of the frequency, treatment, and outcomes of blunt solid organ injury of the abdomen. The large size of the data base and the diverse nature of hospitals, physicians, and patients included in the data set allow comparisons not possible in smaller studies. The goal of this study was to determine the change in frequency of nonoperative management of hepatic and splenic injuries over time and to compare the outcome of these injuries when treated at trauma centers and nontrauma centers. The hypotheses of this study were that (1) the rate of nonoperative management of solid organ injury would increase over time, (2) trauma centers more often treat solid organ injuries nonoperatively than do nontrauma centers, (3) the type of injury could identify patients who would be best served by nonoperative treatment, and (4) patients with injuries selected for nonoperative management would have outcomes comparable to patients treated operatively.

\section{METHODS}

Data were obtained from the state hospital discharge data base. The North Carolina Medical Database Commission was created by state legislative mandate in July 1985. The goal of the data base is to collect data on the utilization, price, and quality of health care services pro- 
vided in the state and to serve as a clearinghouse for the data collected. The Commission has the authority to collect data from all health care providers as well as all thirdparty payers. The available data base consists of approximately 850,000 individual patient discharge records per year from the state's 157 acute care, alcohol rehabilitation, and psychiatric hospitals. The data base contains information about each hospitalization for all patients admitted to the hospitals in the state of North Carolina. Each discharge record includes information about the patient's age, sex, length of stay, diagnoses (the primary diagnosis and four additional ICD-9 coded diagnoses), services provided, related charges, and payer and provider information. The data base's primary goal was the analysis of billing information, but recently, our group has demonstrated that the data base can successfully be used to analyze clinical information. ${ }^{18-20}$

Trauma patients were defined as all patients hospitalized with ICD-9 diagnosis codes between 800 and 959.9. All trauma patients who sustained a solid organ injury of the abdomen (kidney, liver, or spleen) were selected for initial analysis. Analysis of renal injuries showed a consistently high frequency of nonoperative management throughout the course of the study at trauma centers as well as at nontrauma centers (range, $80 \%$ to $90 \%$ for all types of injuries). Because few changes were seen in the management of renal injuries over the course of the study, they were excluded from further analysis. Patients were then included in the study if they had sustained either a splenic or hepatic injury. Patients were defined as having a splenic injury if they had diagnoses of between 865 and 865.19. Open injuries of the spleen were excluded (ICD-9 code 865.0). Patients were defined as having an hepatic injury if they had diagnoses between 864 and 864.19. Open injuries of the liver were excluded (ICD-9 code 864.0).

The ICD-9 coding methodology allows the injury type to be further specified using the fifth digit of the code. The injury types for hepatic and splenic injuries are shown in Table 1.

These injury descriptors were used in the stratification of organ injuries for comparison of the rates of nonoperative management and outcomes. Patients with unspecified or other injuries were grouped together for analysis. The Abbreviated Injury Scale scores and Injury Severity scores were derived from the patients' ICD-9-CM diagnosis codes using a computer lookup method developed by MacKenzie et al. ${ }^{21}$

Patients who had either a hepatic or a splenic injury were classified as undergoing either operative or nonoperative management, based on whether or not an operative procedure was performed on the liver or the spleen, respectively. Patients with splenic injuries were classified as operative patients if any of the procedure codes recorded was equal to 41 . All other patients were classified
Table 1. ICD-9 CODES FOR INJURY TYPE AND SEVERITY

\begin{tabular}{lc}
\hline Injury Description & ICD-9 Code \\
\hline Hepatic injury & \\
Unspecified & 864.10 \\
Hematoma or contusion & 864.11 \\
Minor laceration & 864.12 \\
Moderate laceration & 864.13 \\
Major laceration & 864.14 \\
Other injury & 864.19 \\
Splenic injury & \\
Unspecified & 865.10 \\
Hematoma & 865.11 \\
Capsular tear & 865.12 \\
Parenchymal laceration & 865.13 \\
Massive disruption & 865.14 \\
Other injury & 865.19 \\
\hline
\end{tabular}

as nonoperative patients. In the group of patients sustaining hepatic injury, patients were classified as receiving operative therapy if any recorded procedure code was equal to 50 . The frequency of injuries to the various organs and the operative interventions were analyzed for each year and plotted over time. Frequencies were compared in trauma centers and nontrauma centers.

A major concern before the study was that there might be a number of patients who sustained a solid organ injury that would be operated on for another reason, that is, for pancreatic injury or for a gastric, duodenal, or some other small- or large-bowel injury. In some of these patients, the solid organ injury might not require operative treatment. These patients would have then received an operation but not necessarily operative treatment for their solid organ injury and thus could not be easily classified as either an operatively treated or a nonoperatively treated patient. The rate of this event was found to be low: 15 to 20 cases per year. These patients were excluded from further analysis.

Statistical comparisons of results and outcomes were compared using the SAS system (SAS, Cary, NC) for statistical analysis.

\section{RESULTS}

Over the period of the study, 215,220 hospitalized patients following trauma in 157 hospitals in the state of North Carolina from 1988 through 1992 were available for analysis. This is a rate of approximately 40,000 patients per year out of the approximately 850,000 total annual hospital admissions in the state. Of the 215,220 hospital admissions for injury over a 5-year period, the average number of abdominal injuries was $2013 \pm 196$ per year. The yearly frequency of hepatic and splenic in- 
Table 2. FREQUENCY OF SPLENIC, HEPATIC INJURIES

\begin{tabular}{|c|c|c|c|c|c|}
\hline Year & $\begin{array}{l}\text { State Population } \\
\left(\times 10^{6} \text { population }\right)\end{array}$ & Splenic Injuries & $\begin{array}{c}\text { Rate } \\
\text { (/10 }{ }^{6} \text { population) }\end{array}$ & Hepatic injuries & $\begin{array}{c}\text { Rate } \\
\text { (/10 } \\
\text { population) }\end{array}$ \\
\hline 1988 & 6.481 & 386 & 60 & 361 & 56 \\
\hline 1989 & 6.565 & 505 & 77 & 462 & 70 \\
\hline 1990 & 6.629 & 543 & 82 & 506 & 76 \\
\hline 1991 & 6.749 & 532 & 79 & 550 & 81 \\
\hline 1992 & 6.836 & 553 & 81 & 569 & 83 \\
\hline Total & & 2,519 & & 2,448 & \\
\hline Mean & 6.652 & 504 & 76 & 490 & 73 \\
\hline $5 \mathrm{yr}$ change & +0.355 & +167 & +21 & +208 & +27 \\
\hline
\end{tabular}

juries, the population of the state of North Carolina, and a calculated rate of solid organ injury per capita are shown in Table 2. As demonstrated in the table, the average yearly number of hepatic (490), and splenic (504) injuries were roughly similar during the period studied. The calculated per capita rates of hepatic and splenic injuries increased faster than the rate of increase in the population. Hepatic injuries increased from 56 injuries per million population per year to 83 per million per year in 1992, and splenic injuries increased from 60 per million population per year to 81 per million population per year in 1992. In addition, there was a significant correlation between the population-based frequency of hepatic and splenic injury (Pearson's $R=0.92 ; p=0.001$ ).

The total number of solid organ injuries grouped into those treated at trauma centers and nontrauma centers in the state were analyzed. These results are shown in Tables 3 and 4.

The analysis shows that there was an increase in the number of patients with hepatic injury treated at nontrauma and trauma centers alike $(+30$ and +178 , respectively), but the increases were greater at the trauma centers. The percentage of all hepatic injuries treated at trauma centers increased from $43 \%$ in 1988 to $60 \%$ in 1992, a $15 \%$ increase. Similarly, the number of patients

\begin{tabular}{|c|c|c|c|c|c|}
\hline \multicolumn{6}{|c|}{$\begin{array}{l}\text { Table 3. HEPATIC INJURIES TREATED AT } \\
\text { TRAUMA CENTERS AND AT } \\
\text { NONTRAUMA CENTERS }\end{array}$} \\
\hline Year & $\begin{array}{c}\text { Total } \\
\text { Patients }\end{array}$ & $\begin{array}{c}\text { Nontrauma } \\
\text { Center }\end{array}$ & $\%$ & $\begin{array}{l}\text { Trauma } \\
\text { Center }\end{array}$ & $\%$ \\
\hline 1988 & 361 & 198 & 55 & 163 & 45 \\
\hline 1989 & 462 & 216 & 47 & 246 & 53 \\
\hline 1990 & 506 & 250 & 49 & 256 & 51 \\
\hline 1991 & 550 & 251 & 46 & 299 & 54 \\
\hline 1992 & 569 & 228 & 40 & 341 & 60 \\
\hline Total & 2448 & 1143 & 47 & 1305 & 53 \\
\hline 5 yr change & +208 & +30 & -15 & +178 & +15 \\
\hline
\end{tabular}

with splenic injuries treated at trauma centers increased by $7 \%$, rising from $41 \%$ in 1988 to $48 \%$ in 1992 .

The frequency of the use of nonoperative treatment for solid organ injuries was compared over the 5 -year period of the study. The results are shown in Tables 5 and 6.

As shown, nonoperative management is practiced in a significant number of patients in both injuries studied (63\% of hepatic injuries and $40 \%$ of splenic injuries on average during the 5 years of the study). The rate of nonoperative management in hepatic and splenic injuries increased significantly over the 5 -year period of the study. Nonoperative management of hepatic injuries increased by $15 \%$, from $55 \%$ to $70 \%$, and nonoperative management of splenic injuries increased by $12 \%$, from $34 \%$ to $46 \%$ ( $p=0.001$ for both).

Given the hypothesis that the rates of nonoperative management would be different in trauma centers compared with nontrauma centers, these two groups of patients were separated and analyzed. The results are presented in Tables 7 and 8.

As shown in Tables 7 and 8 and in Figure 1, there was a steady yearly increase in the proportion of patients with splenic and hepatic injury being managed nonoperatively. In patients with hepatic injuries, the rate of nonoperative management increased by $10 \%$ in nontrauma

\begin{tabular}{|c|c|c|c|c|c|}
\hline \multicolumn{6}{|c|}{$\begin{array}{l}\text { Table 4. SPLENIC INJURIES TREATED AT } \\
\text { TRAUMA CENTERS AND AT } \\
\text { NONTRAUMA CENTERS }\end{array}$} \\
\hline Year & $\begin{array}{c}\text { Total } \\
\text { Patients }\end{array}$ & $\begin{array}{c}\text { Nontrauma } \\
\text { Center }\end{array}$ & $\%$ & $\begin{array}{l}\text { Trauma } \\
\text { Center }\end{array}$ & $\%$ \\
\hline 1988 & 386 & 226 & 59 & 160 & 41 \\
\hline 1989 & 505 & 268 & 53 & 237 & 47 \\
\hline 1990 & 543 & 296 & 55 & 247 & 45 \\
\hline 1991 & 532 & 310 & 58 & 222 & 42 \\
\hline 1992 & 553 & 289 & 52 & 264 & 48 \\
\hline Total & 2519 & 1389 & 55 & 1130 & 45 \\
\hline $5 \mathrm{yr}$ change & +167 & +63 & -7 & +104 & +7 \\
\hline
\end{tabular}




\begin{tabular}{|c|c|c|c|c|}
\hline \multicolumn{5}{|c|}{$\begin{array}{l}\text { Table 5. YEARLY DISTRIBUTION OF } \\
\text { OPERATIVE AND NONOPERATIVE } \\
\text { TREATMENT FOR HEPATIC INJURIES }\end{array}$} \\
\hline Year & Nonoperative & Operative & Total & $\%$ Nonoperative \\
\hline 1988 & 198 & 163 & 361 & 55 \\
\hline 1989 & 292 & 170 & 462 & 63 \\
\hline 1990 & 325 & 181 & 506 & 64 \\
\hline 1991 & 331 & 219 & 550 & 60 \\
\hline 1992 & 398 & 171 & 569 & 70 \\
\hline Total & 1544 & 904 & 2448 & 63 \\
\hline 5 yr change & +200 & +8 & +208 & +15 \\
\hline
\end{tabular}

centers and by $18 \%$ in trauma centers $(p=0.01)$. In patients with splenic injuries treated at nontrauma centers, the rate of nonoperative management increased by $9 \%$, whereas in trauma centers the increase was $16 \%(\mathrm{p}=$ 0.001 ). Tables 7 and 8 show that both the absolute yearly rate and the rate of increase in nonoperative management were significantly greater in trauma centers.

It was our hypothesis that the selection of patients for nonoperative treatment would be related to the severity of organ injury. The ICD-9 codes for solid organ injury contain injury descriptors that allow grading of the severity of organ injury (Table 1). Using the ICD-9 code injury descriptors in those patients for whom they were available, the use of nonoperative treatment was assessed. The results of these analyses are shown in Tables 9 and 10.

This analysis demonstrates that there is a significant association between organ injury severity and the rate of nonoperative management for splenic and hepatic injuries. For splenic injuries, nonoperative management ranged from $15 \%$ for massive disruption of the spleen to $86 \%$ for splenic hematomas. The rate of nonoperative management of splenic injury increased significantly during the study period. Nonoperative management of hematomas increased by $6 \%$, capsular tears by $9 \%$, lacerations by $19 \%$, and massive disruption by $6 \%$. In patients

\begin{tabular}{|c|c|c|c|c|}
\hline \multicolumn{5}{|c|}{$\begin{array}{l}\text { Table 6. YEARLY DISTRIBUTION OF } \\
\text { OPERATIVE AND NONOPERATIVE } \\
\text { TREATMENT FOR SPLENIC INJURIES }\end{array}$} \\
\hline Year & Nonoperative & Operative & Total & \% Nonoperative \\
\hline 1988 & 131 & 255 & 386 & 34 \\
\hline 1989 & 180 & 325 & 505 & 36 \\
\hline 1990 & 203 & 340 & 543 & 37 \\
\hline 1991 & 230 & 302 & 532 & 43 \\
\hline 1992 & 256 & 297 & 553 & 46 \\
\hline Total & 1000 & 1519 & 2519 & 40 \\
\hline 5 yr change & +125 & +42 & +167 & +12 \\
\hline
\end{tabular}

\begin{tabular}{|c|c|c|}
\hline \multicolumn{3}{|c|}{$\begin{array}{l}\text { Table 7. NONOPERATIVE MANAGEMENT } \\
\text { OF HEPATIC INJURIES AT TRAUMA } \\
\text { CENTERS AND NONTRAUMA CENTERS }\end{array}$} \\
\hline Year & Nontrauma Centers (\%) & Trauma Centers (\%) \\
\hline 1988 & 54 & 56 \\
\hline 1989 & 56 & 70 \\
\hline 1990 & 67 & 61 \\
\hline 1991 & 58 & 62 \\
\hline 1992 & 64 & 74 \\
\hline 5 yr change & +10 & +18 \\
\hline
\end{tabular}

in the Other/Unspecified group, the nonoperative management rate was high at $52 \%$. This was second only to the $86 \%$ nonoperative management rate for splenic hematomas. The 5-year trend in the Other/Unspecified group was more erratic than the others, but overall, there was still a $14 \%$ increase over time in the rate of nonoperative management, from $40 \%$ in 1988 to $54 \%$ in 1992 .

In hepatic injuries, nonoperative management ranged from $41 \%$ for major lacerations to $93 \%$ for hematomas of the liver. Changes in the rates of nonoperative management for hepatic injuries were localized primarily to patients with hematomas or minor lacerations and those in the Other/Unspecified group. Hematomas of the liver were managed nonoperatively $95 \%$ of the time in the last year of the study, an increase of $2 \%$ from 1988. Nonoperative management of minor lacerations increased by $25 \%$, the largest change in the management of hepatic injuries. As the grade of injury severity increased, the rate of nonoperative management decreased. In the Other/ Unspecified group, the rate of nonoperative management increased 23\%, from $45 \%$ in 1988 to $68 \%$ in 1992 .

The analysis delineates the effects of time on the use of nonoperative treatment. For splenic hematomas, capsular tears, lacerations, and massive disruption of the spleen, there is a statistically significant increased frequency of nonoperative management over time $(\mathrm{p}<=$ 0.01 for all). The analysis of hepatic injuries showed that hematomas, minor lacerations, and other/unspecified

\begin{tabular}{lcc}
\hline \multicolumn{3}{c}{$\begin{array}{c}\text { Table 8. } \\
\text { OF SPLENIC INJURIES AT TRAUMA } \\
\text { CENTERS AND NONTRAUMA } \\
\text { CENTERS }\end{array}$} \\
\hline Year & Nontrauma Centers (\%) & Trauma Centers (\%) \\
\hline 1988 & 35 & 33 \\
1989 & 31 & 41 \\
1990 & 36 & 39 \\
1991 & 40 & 48 \\
1992 & 44 & 49 \\
$5 \mathrm{yr}$ change & +9 & +16 \\
\hline
\end{tabular}




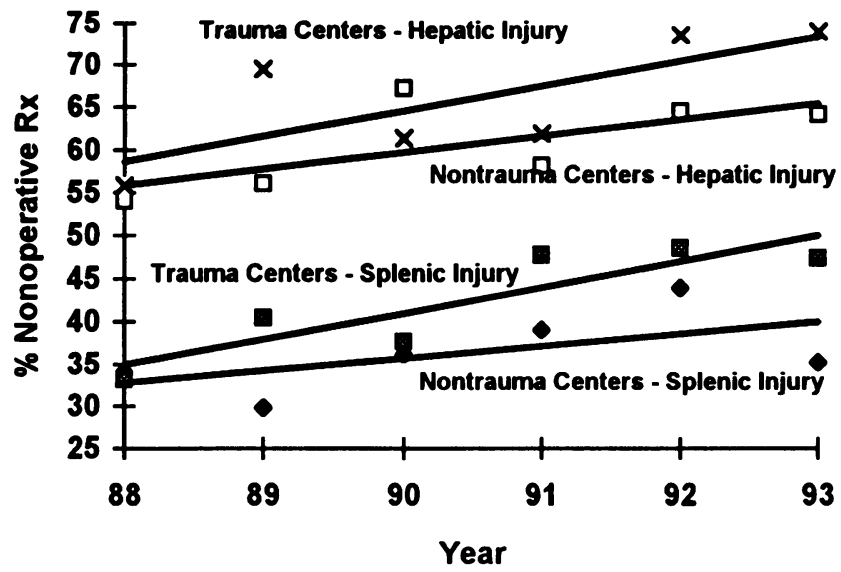

Figure 1. Regression analyses of the rate of nonoperative treatment of hepatic and splenic injury at trauma centers and nontrauma centers.

injuries were each associated with increasing rates of nonoperative management $(\mathrm{p}=0.01)$.

To further investigate the use and the outcomes of nonoperative treatment for solid organ injury in the state, a number of other factors related to hepatic and splenic injuries were analyzed. The results are shown in Tables 11 and 12 and Figures 2 and 3.

In patients with hepatic injuries, nonoperative treatment for all injury types except major laceration led to better outcomes than operation ( $p<0.05$ for all). Similarly, in patients sustaining splenic injuries, nonoperative management was associated with better survival in all injury-type subgroups ( $p<0.01$ for all). Analysis of the other outcome variables assessed, including hospital charges and length of hospital stay, except for hepatic injury patients with minor or moderate lacerations, showed similar findings, with shorter stays and lower charges in the nonoperatively treated patients.

Another major concern over the use of nonoperative treatment for solid organ injury is the potential that during continued observation, the patient will be transfused in an attempt to avoid operation, exposing the patient to the risk of transfusion-associated complications. To assess blood use, the charges for blood use for each subgroup were analyzed. The results shown in Tables 11 and 12 demonstrate that in every category, the charges for blood use are lower for nonoperatively treated than for operatively treated patients.

Given the consensus that most mild injuries can be successfully managed nonoperatively and that only the more severe injuries require surgery, the rates of nonoperative management of the most severe injuries were analyzed. As shown in Figure 4, analysis of the rate of nonoperative management for massive disruption of the spleen at trauma centers and at nontrauma centers demonstrates a marked trend toward nonoperative treatment. The data demonstrate that even for massive splenic injuries as determined by discharge codes, nonoperative management is increasing ( $p<0.05$ for both). In addition, linear regression analyses for the two groups demonstrate that the use of nonoperative treatment for massive disruption of the spleen is increasing fastest in trauma centers. Using the linear regression equations derived from the 5 years of the study, the rates for the subsequent 5 years can be predicted. These results are shown in Figure 4.

Regression modeling demonstrates that on the basis of the 5 years of the current study, the rate of nonoperative treatment of severe splenic injury can be expected to increase. Given the prevailing opinion that splenectomy is the most appropriate management of severe splenic injury, the expected increase in the rates of nonoperative treatment to nearly $40 \%$ predicted by 1997 for trauma centers will need to be compared with actual treatment.

\section{DISCUSSION}

Operative management of blunt abdominal injury has been the purview of the general surgeon since the early 20 th century, when surgery first became available as the mode of treatment for serious abdominal injuries. The critical decision in the care of the patient who has sustained serious blunt abdominal injury is whether to pro-

Table 9. ORGAN INJURY SEVERITY AND RATE OF NONOPERATIVE MANAGEMENT IN HEPATIC INJURY

\begin{tabular}{lccccc}
\hline Year & Hematoma (\%) & $\begin{array}{c}\text { Minor } \\
\text { Laceration (\%) }\end{array}$ & $\begin{array}{c}\text { Moderate } \\
\text { Laceration (\%) }\end{array}$ & $\begin{array}{c}\text { Major } \\
\text { Laceration (\%) }\end{array}$ & $\begin{array}{c}\text { Other/ } \\
\text { Unspecified (\%) }\end{array}$ \\
\hline 1988 & 94 & 54 & 67 & 44 & 45 \\
1989 & 95 & 67 & 46 & 43 & 38 \\
1990 & 93 & 79 & 48 & 37 & 57 \\
1991 & 86 & 66 & 52 & 41 & 58 \\
1992 & 95 & 79 & 58 & 41 & 52 \\
Mean & 93 & 69 & -9 & -3 & +23 \\
5 yr change & +2 & +25 & & & \\
\hline
\end{tabular}


Table 10. ORGAN INJURY SEVERITY AND RATE OF NONOPERATIVE MANAGEMENT IN SPLENIC INJURY

\begin{tabular}{lccccc}
\hline Year & Hematoma (\%) & $\begin{array}{c}\text { Capsular } \\
\text { Tear (\%) }\end{array}$ & Laceration (\%) & $\begin{array}{c}\text { Massive } \\
\text { Disruption (\%) }\end{array}$ & $\begin{array}{c}\text { Other/ } \\
\text { Unspecified (\%) }\end{array}$ \\
\hline 1988 & 82 & 38 & 25 & 13 & 40 \\
1989 & 85 & 34 & 4 & 11 & 61 \\
1990 & 85 & 31 & 30 & 17 & 49 \\
1991 & 89 & 43 & 36 & 14 & 58 \\
1992 & 88 & 47 & 44 & 19 & 54 \\
Mean & 86 & 38 & 28 & 15 & +14 \\
5 yr change & +6 & +9 & +19 & +6 & \\
\hline
\end{tabular}

ceed with operation. Delays or errors in judgment can result in serious patient morbidity or even mortality.

Recent developments in the care of injured patients are changing physicians' practice patterns. One of the recent major changes in trauma care has been the routine use of CT scanning for the evaluation of the injured abdomen. Along with the ability to obtain images of injured abdominal organs has come the ability to quantitate the organ injury severity and the option of selecting nonoperative management for some cases. ${ }^{5,6,8,9,36}$ This approach may be of greatest applicability in the case of solid organ injury. Before the availability of CT scanning, abdominal injury was often assessed by physical examination or diagnostic peritoneal lavage.

Diagnostic peritoneal lavage has been shown to be useful in trauma patients. ${ }^{2,34,35}$ The primary power as well as the main disadvantage of diagnostic peritoneal lavage is its ability to recognize the presence of blood within the abdomen. Although diagnostic peritoneal lavage is highly sensitive for detecting the presence of intra-abdominal injury, nontherapeutic celiotomy rates of up to
$39 \%$ have been reported in centers using this diagnostic tool. ${ }^{37,38}$ Computed tomography scanning has reinforced the belief that blood in the peritoneum does not always require operative therapy. In solid organ injury, a minor injury may lead to blood in the peritoneum that may not require operative repair. It has been shown that the use of CT scanning in blunt abdominal trauma has decreased the rate of nontherapeutic celiotomy. ${ }^{39}$

Based on this recognition and on clinical expertise, some patients with a solid organ injury documented on CT scan have been treated nonoperatively. Although initially viewed as heretical, nonoperative management for some patients has been shown to be successful. Controversy remains concerning the selection of patients for nonoperative treatment and the risks and benefits of such therapy. Given the previous recommendations favoring operative treatment of abdominal injury, it is not surprising that the new approach to the treatment of blunt solid organ injury is adopted by different surgeons at different rates. One of the most important areas of health care research in America today is the attempt to

Table 11. FACTORS RELATED TO HEPATIC INJURY SEVERITY AND TYPE OF TREATMENT

\begin{tabular}{|c|c|c|c|c|c|c|c|c|c|}
\hline Hepatic Injury & Treatment & $\mathbf{N}$ & $\begin{array}{c}\text { Survival } \\
(\%)\end{array}$ & $\begin{array}{c}\text { Mean } \\
\text { ISS }\end{array}$ & $\begin{array}{c}\text { Mean } \\
\text { Age } \\
(y r)\end{array}$ & $\begin{array}{c}\text { Mean } \\
\text { Abdominal } \\
\text { AlS }\end{array}$ & $\begin{array}{c}\text { Mean } \\
\text { Hospital } \\
\text { Charges } \\
\text { (\$) }\end{array}$ & $\begin{array}{l}\text { Mean } \\
\text { Length } \\
\text { of Stay } \\
\text { (days) }\end{array}$ & $\begin{array}{c}\text { Charges for } \\
\text { Blood Use } \\
\text { (\$) }\end{array}$ \\
\hline \multirow{2}{*}{$\begin{array}{c}\text { Hematoma or } \\
\text { contrusion }\end{array}$} & Nonoperation & 367 & 98 & 12.1 & 33.2 & 2.2 & 12,449 & 9.0 & 240 \\
\hline & Operation & 29 & 97 & 15.0 & 27.1 & 2.6 & 21,821 & 12.0 & 517 \\
\hline \multirow[t]{2}{*}{ Minor laceration } & Nonoperation & 251 & 97 & 14.1 & 30.7 & 2.4 & 25,135 & 15.5 & 670 \\
\hline & Operation & 110 & 95 & 13.2 & 30.0 & 2.5 & 22,359 & 12.0 & 836 \\
\hline \multirow[t]{2}{*}{ Moderate laceration } & Nonoperation & 73 & 93 & 21.4 & 29.5 & 3.9 & 31,468 & 13.9 & 768 \\
\hline & Operation & 64 & 91 & 24.3 & 31.0 & 4.0 & 24,133 & 12.5 & 606 \\
\hline \multirow[t]{2}{*}{ Major laceration } & Nonoperation & 115 & 75 & 28.2 & 31.3 & 4.2 & 35,000 & 13.3 & 1,206 \\
\hline & Operation & 171 & 81 & 27.6 & 30.1 & 4.3 & 36,320 & 14.2 & 1,710 \\
\hline \multirow[t]{2}{*}{ Other } & Nonoperation & 738 & 92 & 14.6 & 28.9 & 2.5 & 25,031 & 13.5 & 694 \\
\hline & Operation & 530 & 89 & 13.1 & 30.6 & 2.6 & 26,725 & 12.7 & 946 \\
\hline
\end{tabular}


Table 12. FACTORS RELATED TO SPLENIC INJURY SEVERITY AND TYPE OF TREATMENT

\begin{tabular}{|c|c|c|c|c|c|c|c|c|c|}
\hline Splenic Injury & Treatment & $\mathbf{N}$ & $\begin{array}{c}\text { Survival } \\
(\%)\end{array}$ & $\begin{array}{l}\text { Mean } \\
\text { ISS }\end{array}$ & $\begin{array}{l}\text { Mean } \\
\text { Age } \\
(\mathbf{y r})\end{array}$ & $\begin{array}{c}\text { Mean } \\
\text { Abdominal } \\
\text { AIS }\end{array}$ & $\begin{array}{c}\text { Mean } \\
\text { Hospital } \\
\text { Charges } \\
\text { (\$) }\end{array}$ & $\begin{array}{l}\text { Mean } \\
\text { Length } \\
\text { of Stay } \\
\text { (days) }\end{array}$ & $\begin{array}{c}\text { Charges for } \\
\text { Blood Use } \\
\text { (\$) }\end{array}$ \\
\hline \multirow[t]{2}{*}{ Hematoma } & Nonoperation & 324 & 98 & 11.1 & 30.2 & 2.1 & 12,693 & 9.4 & 199 \\
\hline & Operation & 52 & 94 & 12.0 & 37.3 & 2.2 & 33,489 & 17.0 & 853 \\
\hline \multirow[t]{2}{*}{ Capsular tear } & Nonoperation & 124 & 94 & 11.7 & 28.4 & 2.2 & 19,625 & 10.7 & 613 \\
\hline & Operation & 197 & 92 & 13.6 & 34.7 & 2.3 & 36,128 & 16.2 & 1,087 \\
\hline \multirow[t]{2}{*}{ Laceration } & Nonoperation & 42 & 93 & 19.5 & 27.9 & 3.1 & 14,494 & 10.9 & 401 \\
\hline & Operation & 98 & 88 & 19.5 & 31.9 & 3.1 & 27,644 & 13.6 & 928 \\
\hline \multirow[t]{2}{*}{ Massive disruption } & Nonoperation & 152 & 94 & 20.7 & 25.7 & 4.0 & 14,374 & 9.2 & 356 \\
\hline & Operation & 869 & 91 & 24.1 & 33.5 & 4.0 & 24,144 & 12.4 & 761 \\
\hline \multirow[t]{2}{*}{ Other } & Nonoperation & 358 & 94 & 14.0 & 28.2 & 2.3 & 26,341 & 16.3 & 571 \\
\hline & Operation & 303 & 87 & 14.2 & 33.5 & 2.4 & 32,772 & 16.6 & 1,076 \\
\hline
\end{tabular}

ISS = Injury Severity Scale; AIS = Abbreviated Injury Scale

understand changes in physicians' practice patterns and how they evolve. ${ }^{22,24,40}$ It was our hypothesis that the management of blunt solid organ injury was changing rapidly, and this was borne out by the study.

Trauma centers have been shown by our group and others ${ }^{28,29,19,41}$ to be associated with improved outcomes in trauma patients. If there is a change in trauma care, it seems reasonable that such change would be led by centers with the greatest interest, experience, and expertise in the care of injury. Thus, if trauma centers provide the best care and if nonoperative management is a new approach that is the best method for treating selected injuries, our hypothesis was that trauma centers are leading the way in this newer approach to the management of solid organ injury.

The purpose of this study was to perform a statewide, population-based, large-scale, time-series analysis of the use of nonoperative management in trauma and to attempt to determine the presence of a change in physicians' practice over the time of the study. The study uses a statewide data base and has advantages over other studies that have addressed the use of nonoperative manage-

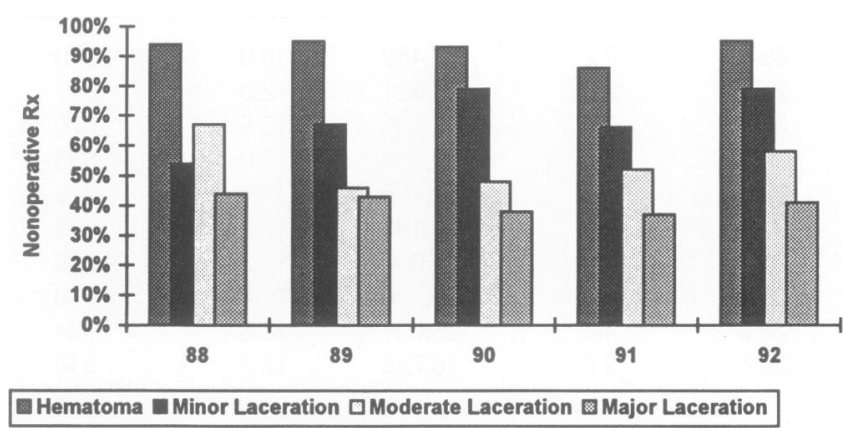

Figure 2. Rate of nonoperative management of hepatic injuries. ment for splenic or hepatic injuries. ${ }^{6-15}$ Prior studies have been from individual hospitals or selected groups of hospitals and therefore may have been biased by the degree of interest or expertise in trauma care by the physicians and hospitals, the referral patterns, or geographic or demographic factors. One of the unique features of the current study is the inclusion of all hospitals and all admitted trauma patients from the entire state of North Carolina, thus providing a true and unbiased insight into the nature of solid organ injury and its treatment. In addition, because the data in the study covers 5 years, it allows a time-series analysis of the changes in physicians' practice management. Because no previous studies of this scope using such a large population-based data base of trauma patients has, to the best of our knowledge, been published, the current study is unique in its determination of the decreasing numbers of surgical interventions for the management of solid organ abdominal injuries in North Carolina.

The hypotheses that led to this study were as follows: (1) that nonoperative management of solid organ injury was increasing, (2) that nonoperative management was

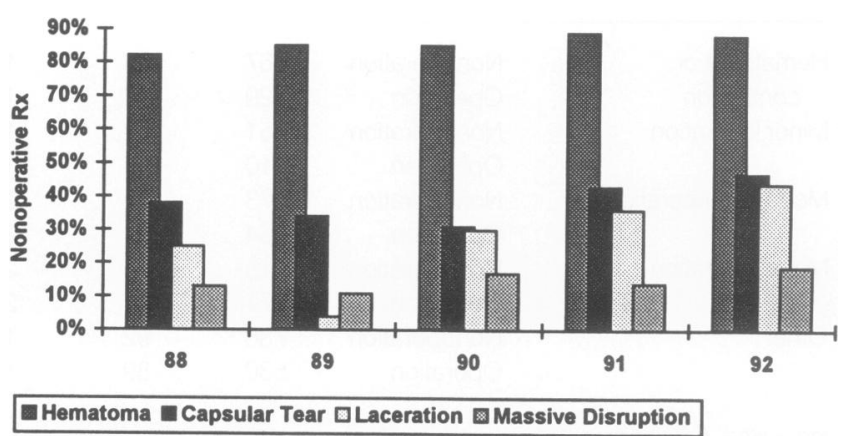

Figure 3. Rate of nonoperative management of splenic injuries. 


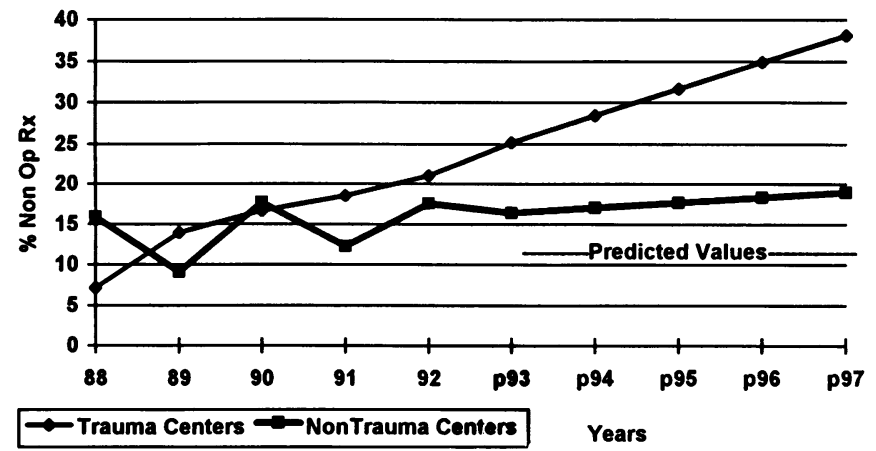

Figure 4. Regression model of predicted values for the use of nonoperative management of the massively disrupted spleen based on the 5 years from 1988 through 1992.

more common at trauma centers than at nontrauma centers, (3) that selection of patients for nonoperative management would be related to the severity of the injury, and (4) that the outcome of nonoperative treatment would be comparable to that of operative treatment. Review of the results demonstrates that each hypothesis was confirmed. As shown in Table 1, the population of North Carolina grew from 6.48 million to 6.84 million during the time of this analysis. The incidence of hepatic and splenic injury also rose in this time, but at a rate greater than the population increase (from 60 to 81 splenic injuries per 1 million population and from 56 to 83 hepatic injuries per 1 million population). The change in the rates of hepatic and splenic injuries is very highly correlated $(R=0.92)$, suggesting that the injury events are related. Again, it is worth noting the large size of the study population available for this analysis.

The rising frequency of hepatic and splenic injuries documented in this study may have a significant effect on the health care system. Table 2 demonstrates that although the eight trauma centers make up only a small portion of the 157 hospitals in the state $(5 \%)$, they care for a large proportion of patients with solid abdominal injuries (55\% of splenic injuries and 53\% of hepatic injuries). This disproportionate experience in the care of injured patients may affect the skills and experience available for the care of seriously injured patients at individual hospitals. Because numerous studies have shown that increased experience in caring for an illness increases efficiency and improves outcomes, ${ }^{28-30}$ one could conclude that regionalization of trauma care is advantageous for the state and its citizens. During the study period, the number of solid organ injury patients being cared for by trauma centers increased from $41 \%$ to $48 \%$ of splenic injuries and from $45 \%$ to $60 \%$ of hepatic injuries, so it appears that there is a trend toward increased utilization of the trauma center as the site for the treatment of serious injury. Although this may be of value in terms of care and outcome, trauma care is generally expensive, resource intensive, and poorly reimbursed as well as disruptive to regular hospital scheduling and activities. ${ }^{31,32}$ If the commitment to an increased level of care in trauma centers is to continue, it must be recognized and supported by society.

The use of nonoperative management for the care of patients with solid organ injury was assessed for the 5 years of the study. In both liver and splenic injury, the rate of nonoperative management increased significantly. In patients with hepatic injury, the rate increased from $55 \%$ in 1988 to $70 \%$ in 1992 . In patients sustaining splenic injury, the rate of nonoperative treatment increased from $34 \%$ to $46 \%$. This is a remarkable change in practice patterns by the surgeons in the state over a relatively short period of time. A number of studies have explored the process of changing physicians' practices. ${ }^{22,24,25}$ In general, it has been found that interventions designed to change physicians' practices have had little success. ${ }^{28}$ Therefore, the changes in the management of blunt abdominal injuries documented in this study bear further evaluation as a possible model of how physician practices can change rapidly, based on reports in the scientific literature, the institution of newer technology, and the recognition of improved outcomes associated with new approaches to care. It is also worth noting that the change in the care of the injured patients documented in this study occurred despite a predictable decrease in professional reimbursement for the attending surgeon, making it all the more remarkable that this pervasive change is sweeping the state.

Analysis of the rate of nonoperative management in trauma centers and nontrauma centers is shown in Table 4. It was our hypothesis that this newer approach to the care of patients with solid organ injury might be led by those with the greatest experience and interest in the field of trauma. In this study, trauma centers had consistently higher rates of nonoperative treatment of patients with splenic and hepatic injuries. The higher rates and the higher rate of increase in the use of this technique at the state's trauma centers is consistent with the hypothesis that the trauma centers, through their increased experience and interest in trauma care and their increased capability for careful monitoring, are leading the way in the development of this newer approach to the management of blunt abdominal injury. However, the use of nonoperative management of solid organ injury is not far behind in nontrauma centers.

In the analysis of the relationship of the organ and severity of injury to the use of nonoperative management, it was found that in injury of the spleen and liver there was a clear association with the type of organ injury sustained and the frequency of nonoperative management. Splenic hematomas were managed nonoperatively in $86 \%$ of patients. Capsular tears, lacerations and massive disruptions had progressively lower rates of nonopera- 
tive management (38\%, $28 \%$ and $15 \%$ respectively). In the "other/unspecified" group, the rate of nonoperative management was over $50 \%$. In each of the more severe types of injury, the rate of nonoperative management has been increasing over the period of the study $(p=0.01$ or less in each). In patients with massive disruption of the spleen, the rate of nonoperative management increased from $13 \%$ to $19 \%(p=0.001)$. In patients sustaining hepatic injuries, the relation between injury type and severity and the use of nonoperative management is again quite clear The use of nonoperative management ranged from $93 \%$ in patients with hepatic hematomas or contusions to $41 \%$ in patients with major lacerations ( $p=$ 0.001 ). There was a large increase in the rate of nonoperative management for minor lacerations and for patients in the "other/unspecified" groups (25\% and $23 \%$ respectively). Hepatic hematomas are near the upper limit of nonoperative management at $95 \%$ of patients by the last year of the study. Excluding the first year of the study for patients with moderate hepatic lacerations, the rate of nonoperative management went from $46 \%$ in 1989 to $58 \%$ in 1992 a $12 \%$ increase.

In the analyses, nonoperative management tended to have better outcomes for all patients who sustained hepatic injuries, except for those patients with major lacerations ( $p<0.05$ for all). Similarly, in patients sustaining splenic injuries, nonoperative management resulted in better survival in all injury-type subgroups $(p<0.01$ for all). In the analysis of the other outcome variables, hospital charges and length of hospital stay showed similar findings, with shorter stays and lower charges for the nonoperatively treated patients. The implications of these findings are that in selected patients, nonoperative management can result in outcomes that are comparable to, and perhaps even better than, operative treatment.

A major concern in the use of nonoperative treatment of solid organ injury is the potential for excessive transfusion during observation. This fear is related to the possibility of patients being unnecessarily exposed to the risk of transfusion-associated complications. This concern is based on some of the first studies of nonoperative management of the spleen in children. ${ }^{7,8,23}$ In these studies, large volumes of blood were transfused in efforts to avoid surgery. On the other hand, transfusion requirements of those patients undergoing surgery have not been compared with those treated nonoperatively. Although it has been the general assumption that direct surgical intervention will definitively treat the injury and thus stop all bleeding, it is also evident that blood loss may occur during surgery and, in some cases, after surgery, so that surgical therapy may also be associated with significant transfusion requirements. The current study, to the best of our knowledge, is the first to present a large-scale comparison of blood use in operative and nonoperative patients with roughly comparable injuries. To assess blood use, the charges for blood use for each subgroup were analyzed. The results demonstrate that in all categories, charges for blood use are lower for nonoperatively treated patients of similar ages, Injury Severity scores, and Abbreviated Injury Scale scores of the abdomen. Although this does not prove the advantage of nonoperative management for every patient, it does suggest that as currently practiced in North Carolina, transfusion rates tend to be lower in patients managed nonoperatively compared with patients managed operatively with similar levels of organ injury severity.

An intriguing finding of the current study is the increasing frequency of the use of nonoperative management of more severe solid organ injuries. Although there has been a gradual development of consensus on the value of nonoperative management for milder solid organ injuries, nonoperative management for the treatment of more severe injuries remains highly controversial. This is particularly true in severe splenic injuries, in which fears of massive uncontrolled hemorrhage or delayed splenic rupture are important factors in patient management decisions. Given this controversy, it is of note that the data in this analysis seem to show that even for the most severe splenic injuries, the rate of nonoperative management is increasing and that in North Carolina this increase appears to be led by the eight trauma centers.

It is important to point out, however, that nonoperative management of solid organ injury is labor intensive, requiring satisfactory patient monitoring and availability of diagnostic studies. Additionally, expectant management of solid organ injury requires constant availability of operating rooms and personnel in the event of urgent or emergent operative intervention. Trauma centers are better equipped to provide the necessary monitoring and therapeutic options for solid organ injury. This may explain, in part, the increasing trend toward nonoperative management in trauma centers compared with nontrauma centers.

Regression modeling was used in this time-series analysis to predict future trends in nonoperative management in the state. Assuming that this trend is linear over the 5 years of the study, it can be predicted that by 1997 , the rate of nonoperative management for the most severe splenic injuries could rise to nearly $40 \%$ in trauma centers. For this to occur, the increasing frequency of nonoperative management of severe splenic injuries must plateau at some point. It is interesting, however, that there has been such a significant rate of increase for this treatment modality by trauma centers in patients with significant splenic injury. The finding that the frequency of nonoperative management for severe splenic injury has not changed in nontrauma centers is not surprising. Nontrauma centers have limited capabilities to offer nonoperative options for these difficult patients. 


\section{Limitations}

There are several limitations to this study, the first being the nature of the data source. First, this data base was primarily designed for billing purposes, not to answer specific questions regarding patient management and physicians' practice patterns. Second, all data entry was performed by nonmedical personnel. Their lack of clinical expertise may be a source of error, especially in the grading of injury severity. Indirect evidence of this is indicated by the relatively large number of injuries classified as "other" or "unspecified" (52\% of hepatic injuries and $26 \%$ of splenic injuries). Finally, conclusions for outcomes (mortality and length of stay should be interpreted cautiously, because there is limited stratification for injury severity.

Overall, this study demonstrates that for appropriately selected patients, nonoperative management can result in excellent outcomes, comparable to those of operative management. It appears that this approach to therapy of solid organ injury will continued to be used, because the rate of nonoperative management for all types of hepatic and splenic injuries have increased over the course of this study. Clearly, not all patients can be managed nonoperatively. Continued work will be needed to identify the ideal selection criteria for this treatment approach. In the interim, nonoperative management is a viable option for the management of all types of solid organ injury.

\section{Conclusions}

It is increasingly incumbent on health care providers to ensure that treatments delivered to patients are the most efficient and effective possible. With the development of large-scale, population-based data bases, it is now possible to assess the effectiveness and efficiency of nonoperative management of splenic and hepatic injuries through studies of patient outcomes. Recent developments in the ability to assess intra-abdominal injuries without surgical exploration have led to a reduced reliance on surgical procedures as diagnostic and management tools.

The current study demonstrates that nonoperative management of hepatic and splenic injury is increasing. It further demonstrates improving outcomes of patients of similar injury severity when they are managed nonoperatively. We believe, even in this initial effort to assess outcomes, that nonoperative management of splenic and hepatic injuries leads to favorable results.

This study also demonstrates that in North Carolina, trauma centers appear to be the first-line respondents to these changes and improvements in treatment of hepatic and splenic injuries. This finding is consistent with the hypothesis that changes in trauma patient management are led by trauma centers.

\section{References}

1. Committee on Trauma Research. National Research Council, and the Institute of Medicine: Injury in America. Washington, DC: National Academy Press, 1985.

2. Root HC, Hauser CW, McKinley CR, et al. Diagnostic peritoneal lavage. Surgery $1965 ; 57: 633-637$.

3. Davis RA, Shayne JP, Max MH, et al. The use of computerized axial tomography versus peritoneal lavage in the evaluation of blunt abdominal trauma: a prospective study. Surgery 1985; 98 : 845-849.

4. Fabian TC, Mangiante EC, White TJ, et al. A prospective study of 91 patients undergoing both computed tomography and peritoneal lavage following blunt abdominal trauma. J Trauma 1986; 26: 602-608.

5. Buntain WL, Gould HR, Maull KI. Predictability of splenic salvage by computed tomography. J Trauma 1988; 28:24-34.

6. Mirvis SE, Whitley NO, Vainwright JR, Gens DR. Blunt hepatic trauma in adults: CT-based classification and correlation with prognosis and treatment. Radiology 1989; 171:27-32.

7. Upadhyaya P, Simpson JS. Splenic trauma in children. Surg Gynecol Obstet 1988; 128:781-790.

8. Pearl RH, Wesson DE, Spence LJ, et al. Splenic injury: a 5-year update with improved results and changing criteria for conservative management. J Ped Surg 1989; 24:428-431.

9. Cywes S, Rode H, Millar AJW. Blunt liver trauma in children: nonoperative management. J Ped Surg 1985; 20:14-18.

10. Meyer AA, Crass RA, Lim RL, et al. Selective nonoperative management of blunt liver injury using computed tomography. Arch Surg 1985; 120:550-554.

11. Smith JS, Wengrovitz MA, DeLong BS. Prospective validation of criteria, including age, for safe, nonsurgical management of the ruptured spleen. J Trauma 1992; 33:363-369.

12. Witte CL, Esser MJ, Rappaport WD. Updating the management of salvageable splenic injury. Ann Surg 1992; 215:261-265.

13. Villalba MR, Howells GA, Lucas RJ, et al. Nonoperative management of the adult ruptured spleen. Arch Surg 1990; 125:836-839.

14. Tom WW, Howells GA, Bree RL, et al. A nonoperative approach to the adult ruptured spleen sustained from blunt trauma. Am Surg 1984; 51:367-371.

15. Bynoe RP, Bell RM, Miles WS, et al. Complications of nonoperative management of blunt hepatic injuries. J Trauma 1992; 32: 308-315.

16. Pachter HL, Spencer FC, Hofstetter SR, et al. Significant trends in the treatment of hepatic trauma: experience with 411 injuries. Ann Surg 1992; 215:492-500.

17. Hammond JC, Canal DF, Broadie TA. Nonoperative management of adult blunt hepatic trauma in a municipal trauma center. Am Surg 1992; 58:551-555.

18. Fakhry SM, Rutledge R, Dahners LE, Kessler D. Incidence, management, and outcome of femoral shaft fracture: a statewide population-based analysis of 2805 adult patients in a rural state. $\mathbf{J}$ Trauma 1994; 37:255-261.

19. Rutledge R, Fakhry SM, Meyer AA, et al. An analysis of the association of trauma centers with per capita hospitalizations and death rates from injury. Ann Surg 1993; 218:512-523.

20. Rutledge R, Fakhry SM, Baker CC, Oller D. Injury severity grading in trauma patients: a simplified technique based upon ICD-9 coding. J Trauma 1993; 35:497-506.

21. MacKenzie EJ, Steinwachs DM, Shenkar B. Classifying trauma severity based on hospital discharge diagnosis. Med Care 1989; 27 : 412-422.

22. Welch HG, Miller ME. Physician profiling: an analysis of inpatient practice patterns in Florida and Oregon. N Engl J Med 1994; 313: 607-612.

23. Lally KP, Rosario V, Mahour GH, Woolley MM. Evolution in the 
management of splenic injury in children. Surg Gynecol Obstet $1990 ; 170: 245-248$.

24. Ayanian JZ, Hauptman PJ, Guadagnoli E, et al. Knowledge and practices of generalist and specialist physicians regarding drug therapy for acute myocardial infarction. N Engl J Med 1994; 331: 1136-1142.

25. Lamas GA, Pfeffer MA, Hamm P, The SAVE Investigators, et al. Do the results of randomized clinical trials of cardiovascular drugs influence medical practice? N Engl J Med 1972; 327:241-247.

26. Lomas J, Anderson GM, Domnick-Pierre K, et al. Do practice guidelines guide practice? the effect of a consensus statement on the practice of physicians. N Engl J Med 1989; 321:1306-1311.

27. John TG, Naylor AR, Howlett J, et al. An audit of trends and current practices of carotid endentectomy in Edinburgh (1975-1990). J R Coll Surg Edinb 1993; 38:138-141.

28. Hannan EL, Kilburn H Jr., O'Donnell JF, et al. A longitudinal analysis of the relationship between in-hospital mortality in New York State and the volume of abdominal aortic aneurysm surgeries performed. Health Serv Res 1992; 27:517-542.

29. West JG, Williams MJ, Trunkey DD, Wolforth CC Jr. Trauma systems: current status-future challenges. JAMA 1988; 259: 3597-3600.

30. Champion HR, Sacco WJ, Copes WS. Improvement in outcome from trauma center care. Arch Surg 1991; 8:333-338.

31. Joy SA, Lichtig LK, Knauf RA, et al. Identification and categorization of and cost for care of trauma patients: a study of 12 trauma centers and 43,219 Statewide patients. J Trauma 1994; 37:303308.

32. Clancy TV, Messick LN, Covington D, et al. The financial impact of intentional violence on community hospitals. J Trauma 1994; 37:1-4.

33. Kapp MB. The legal status of clinical practice parameters: an annotated bibliography. Am J Med Quality 1993; 8:24-27.

34. Hawkins ML, Bailey RL Jr., Carraway RP. Is diagnostic peritoneal lavage for blunt trauma obsolete? Am Surg 1990; 56:96-99.

35. Gomez GA, Alvarez R, Plasencia G, et al. Diagnostic peritoneal lavage in the management of blunt abdominal trauma: a reassessment. J Trauma 1990; 27:1-5.

36. Sugrue M, Knox A, Sarre R, et al. Management of splenic trauma: a new CT-guided splenic injury grading system. Aust N Z J Surg 1991; 61:349-353.

37. Drost TF, Rosemurgy AS, Kearney RE, Roberts D. Diagnostic peritoneal lavage: limited indications due to evolving concepts in trauma care. Am Surg 1991; 57:126-128.

38. Miller FB, Cryer HM, Chilikuri S, et al. Negative findings on laparotomy for trauma. South Med J 1987; 82:1231-1234.

39. Sorkey AJ, Farnell MD, Williams HJ Jr., et al. The complementary rules of diagnostic peritoneal lavage and computed tomography in the evaluation of blunt abdominal trauma. Surgery 1989; 106:794800 .

40. Greco PJ, Eisenberg JM. Changing physicians' practices. N Engl J Med 1993; 329:1271-1273.

41. Rutledge R, Messick J, Baker CC, et al. Multivariate populationbased analysis of the association of country trauma centers with per capita country trauma death rates. J Trauma 1992; 33:27-37.

\section{Discussion}

DR. BASIL A. PRUITT, JR. (Fort Sam Houston, Texas): Dr. Rutledge and his colleagues have presented another in their series of papers from the department of surgery at the University of North Carolina which documents the usefulness and importance of a trauma registry and the power of population-based data collection systems. This report confirms both the leader- ship role of trauma centers in bringing about changes in the care of the injured patient and the cost-effectiveness of such centers.

I have some questions, the answers to which are needed to interpret some of the information presented.

What explains the difference in trauma center referral for patients with hepatic injury and those with splenic injury?

Does the overall decrease rather than increase in nonoperative management for moderate and major hepatic injury during the 5-year study period mean that the need for operation is now more rapidly and accurately determined at trauma centers and thereby provide further justification for regional trauma centers?

What explains the higher hospital charges for nonoperative management of patients with minor and moderate hepatic lacerations?

How comfortable are you with the prediction of an ever-increasing rate of nonoperative management at trauma centers? It seems likely that there will be some irreducible subset of patients who will have such severe injury that operation will always be required.

Do the observed management trends correlate with staff member advanced trauma life support verification as well as for trauma center locale?

I compliment the authors on generating these data, which provide the financial basis supporting inclusion of trauma centers as an integral component of managed-care systems wherein their documented leadership in effecting improvements in care should lead to progressively better outcomes at progressively lesser overall costs.

DR. LewiS M. FLiNT, JR. (New Orleans, Louisiana): I enjoyed listening to this paper. I have some biases in this area in that this study represents trauma anthropology, if you willor maybe better stated, the "Gorillas in the Mist" approach to trauma research wherein you try to deduce the behavior of a species by observing its behavior.

I am not so sure that we can take much comfort from the fact that the frequency of nonoperative therapy of solid organ injuries is increasing. The fact that it is increasing in the trauma centers, comfortably leads to the conclusion that trauma centers are setting the pace in this area. I should certainly hope so.

I wonder, however, if we are really getting the kind of return on investment that we deserve out of the analysis of these large data sets. For example, would it not be better to find out whether nonoperative therapy for solid organ injury is successful? For example, could you not ask the database to tell you whether spleen injuries were managed without operation, with no transfusion, with no adverse modification of the care of other injuries, and a hospital stay of less than 5 days? These are pretty well accepted measures of success of nonoperative management of splenic injury.

I have only a couple of minor questions about the data.

How do you know there actually was a spleen or liver injury? Did all of the patients get computed tomography scans? Or were some of the patients managed by clinical evidence alone?

Finally, how many patients in the data set were actual multiple injury patients as opposed to isolated solid organ injury patients? 